\title{
Aerodynamics Characteristics of an Innovative Large Turboprop Through Wind Tunnel Tests Including Propulsive Effects
}

\author{
S. Corcione ${ }^{1}$, F. Nicolosi ${ }^{2}$, D. Ciliberti ${ }^{3}$, V. Cusati ${ }^{4}$ \\ University of Naples Federico II, Naples, 80125, Italy
}

\begin{abstract}
This paper deals with the assessment of both longitudinal and directional aerodynamic characteristics of an innovative large capacity turboprop aircraft by means of a wind tunnel test campaign on a scaled model. The aircraft under investigation is an innovative turboprop platform providing for a three lifting surface layout and a rear engine installation. The scope of this research is to deeply investigate the aerodynamic behavior of such an innovative platform to assess the aerodynamic interferences among the aircraft components. In particular, the effects of the third lifting surface (the canard), installed in front of the main wing, must be carefully investigated to have a reliable estimate of the aircraft stability and controllability characteristics. This innovative platform provides for a rear engine installation at the tip of the horizontal tailplane. Thus, a specific experimental campaign has been dedicated to investigating the aircraft aerodynamic characteristics in power on conditions.
\end{abstract}

\section{Nomenclature}

$\eta \quad=$ Propeller efficiency

$b \quad=$ Reference span for wind tunnel aerodynamic coefficients calculation

$c=$ Reference mean wing chord for wind tunnel aerodynamic coefficients calculation

$i_{H} \quad=$ Horizontal tail plane root incidence angle

$C_{L \max }=$ Aircraft maximum lift coefficient at a generic condition

$C_{L \alpha}=$ Lift coefficient derivative with respect to the angle of attack

$C_{M C L}=$ Pitching moment coefficient derivative with respect to the aircraft lift coefficient

$C_{N \beta} \quad=$ Yawing moment coefficient derivative with respect to the sideslip angle

$C_{P} \quad=$ Propeller power coefficient

$C_{T} \quad=$ Propeller thrust coefficient

$D=$ Propeller diameter

$E=$ Aircraft aerodynamic efficiency at a generic condition

$J \quad=$ Propeller advance ratio

$K_{v} \quad=$ Electric motor constant

$n=$ Propeller revolutions per second

$N=$ Propeller normal force

$P \quad=$ Propeller power

$q \quad=$ Dynamic pressure

Re $\quad=$ Reynolds number

$S \quad=$ Reference surface for wind tunnel aerodynamic coefficients calculation

$S_{w} \quad=$ Wing area

$T \quad=$ Propeller thrust

\footnotetext{
${ }^{1}$ Post Doc. Researcher, Department of Industrial Engineering

${ }^{2}$ Associate Professor, Department of Industrial Engineering, AIAA Aircraft Design Technical Committee member

${ }^{3}$ Assistant Professor, Department of Industrial Engineering

${ }^{4} \mathrm{PhD}$, Dept. of Industrial Engineering, AIAA student member
} 


$\begin{array}{ll}V_{\infty} & =\text { Undisturbed flow speed } \\ W & =\text { Aircraft weight at a generic condition } \\ \text { DOC } & =\text { Direct Operating Costs } \\ \text { ESC } & =\text { Electronic speed controller } \\ \text { IRON } & =\text { Innovative turbopROp configuratioN } \\ \text { JPAD } & =\text { Java Program for Aircraft Design } \\ \text { mac } & =\text { Wing mean aerodynamic chord } \\ \text { MDAO } & =\text { Multidisciplinary Design Analysis and Optimization } \\ \text { MXCL } & =\text { Maximum climb engine rating } \\ \text { RANS } & \text { Reynolds-Averaged Navier Stokes } \\ \text { RC } & =\text { Remote control } \\ \text { RPM } & =\text { Revolutions per minute }\end{array}$

\section{Introduction}

The present research work is framed in the Innovative turbopROp configuratioN (IRON) project complying with the European Union topic JTI-CS2-2015-CPW02-REG-01-03 (Green and cost-efficient Conceptual Aircraft Design including Innovative Turbo-Propeller Power-plant) as part of the Clean Sky 2 program for Horizon 2020. The topic leader is Leonardo and several core-partners are involved into the project, with CIRA (Italian Aerospace Research Centre) as coordinator.

The project focuses on the feasibility study of an innovative turboprop regional configuration, which is supposed to be competitive with respect to short/medium haul regional jets. The Design of Aircraft and Flight technologies (DAF) research group of the University of Naples Federico II is involved in the preliminary design, aerodynamic analysis, performance evaluation, wind tunnel testing of a scaled model and Direct Operating Cost (DOC) estimation innovative regional aircraft.

Within the IRON project, different design loops with increasing level of complexity and fidelity, have been accomplished, aiming at assessing the design from numerical simulations up to experimental validations. The innovative turboprop configuration, which has been shown in several exhibitions partnered with Clean Sky 2, provides for a three-lifting surface layout with rear-mounted, propeller-driven engines. A summary of the project status, including the last configuration that will be investigated in the wind tunnel, has been presented in Ref. [1]. More details dealing with several design loops, through which the latest configuration has been achieved, have been shown in Refs. [2] to [6].

For the sake of brevity, it is here resumed that the innovative configuration is supposed to be competitive with respect to regional jet on short and medium range, with a load capacity of 130 passengers, a design range of $1600 \mathrm{nmi}$, a cruise Mach number of about 0.65 and a large turboprop engine with a thrust specific fuel consumption $25 \%$ lower than a modern high-bypass ratio geared turbofan. The aircraft three-view is shown in Fig. 1.

This aircraft configuration has been assessed by means of a Multidisciplinary Design Analysis and Optimization (MDAO) performed using in-house software named JPAD [7][8], selecting a three lifting surface layout as the best solution. This configuration is the result of a multidisciplinary analyses and optimization process involving the following disciplines: weight and balance, aerodynamics, stability and control, performance, and DOC. The MDAO process also included several methodologies developed by DAF research group dealing with both vertical tail design and sizing [9][10] and fuselage aerodynamics prediction method [11].

According to the chosen number of design parameters, more than 7000 different aircraft configurations have been generated and analysed to define a response surface to perform the optimization process. Targets of the optimization process have been the cruise parameter $W / E$ (representing the cruise drag) and take-off and landing factors $W /\left(S_{w} C_{L \max }\right)$, which affect the ground performance (i.e. take-off and landing field lengths). Several optimization algorithms have been exploited, including the approach of game theory applied to aircraft design [12][13]. Some of the main geometrical data of the selected three lifting surface aircraft are summarized in Table 1.

To validate stability and control characteristics, wind tunnel tests in prop-off and prop-on conditions have been planned.

A power-off wind tunnel test campaign has been already performed in 2018 on a scaled model of an intermediate configuration of this innovative platform (Sec. III). Some results in terms of longitudinal characteristics have been shown in Ref. [6], while some results dealing with the experimental estimation of the aircraft directional stability have been presented in Ref. [14]. For the latest aircraft configuration, the test article model has been upgraded with new 
lifting surfaces, including movables: wing flaps, elevator, rudder, and canard plain flap. For the power-on wind tunnel tests, the tunnel instrumentation has been upgraded too (Sec. IV).
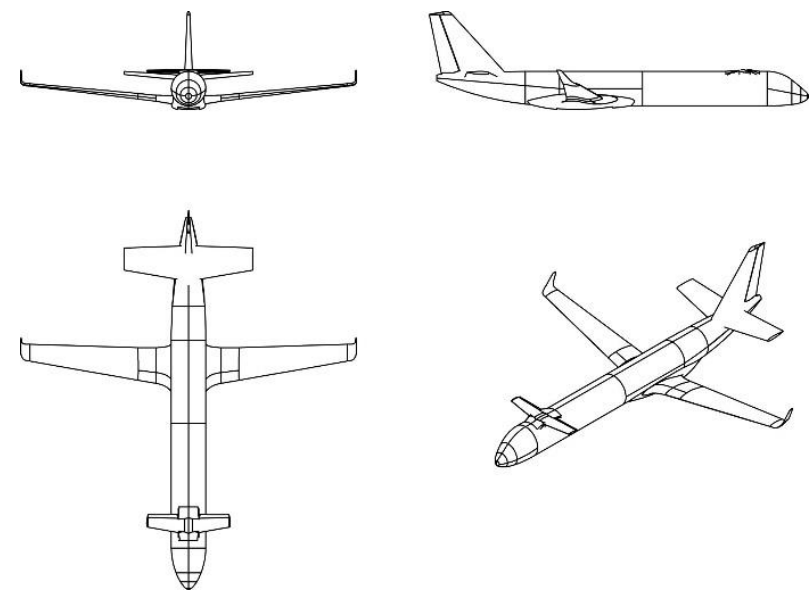

Fig. 1 Latest configuration of the Innovative turbopROp configuration (IRON).

Table 1. Latest aircraft configuration main geometric characteristics.

\begin{tabular}{rlll}
\hline Component & Dimensions & Full scale & $\mathbf{1 : 2 5}$ Scaled model \\
\hline \multirow{2}{*}{ Fuselage } & Max. Diameter & $3.535 \mathrm{~m}$ & $0.141 \mathrm{~m}$ \\
& Length & $38.04 \mathrm{~m}$ & $1.522 \mathrm{~m}$ \\
\hline \multirow{3}{*}{ Wing } & Planform area & $98.6 \mathrm{~m}^{2}$ & $0.158 \mathrm{~m}^{2}$ \\
& Aspect ratio & 12 & 12 \\
& Leading edge sweep angle & $10^{\circ}$ & $10^{\circ}$ \\
\hline \multirow{3}{*}{ Canard } & Planform area & $11.49 \mathrm{~m}^{2}$ & $0.018 \mathrm{~m}^{2}$ \\
& Aspect ratio & 5.57 & 5.57 \\
& Leading edge sweep angle & $10^{\circ}$ & $10^{\circ}$ \\
\hline \multirow{3}{*}{ Horizontal tail } & $38.43 \mathrm{~m}^{2}$ & $0.061 \mathrm{~m}^{2}$ \\
& Planform area & 4.4 & 4.4 \\
& Aspect ratio & $10^{\circ}$ & $10^{\circ}$ \\
\hline & Leading edge sweep angle & $24.45 \mathrm{~m}^{2}$ & \\
& Planform area & 1.36 & 1.36 \\
& Aspect Ratio & $45^{\circ}$ & $45^{\circ}$ \\
\hline
\end{tabular}

For a sake of clarity, this paper shows a compendium of the most relevant results achieved by the experimental campaign performed on the intermediate aircraft configuration in order to highlight the main drivers that have led to significant modifications to the aircraft configuration. The sizing of the scaled propulsive system as well as the necessary wind tunnel hardware upgrades are also presented in this paper. The complete experimental investigation about the aerodynamic behaviour of the latest aircraft configuration, including propulsive effects, was expected to be completed by the end of April 2020, unfortunately due to the Coronavirus disease (COVID-19) outbreak, the experimental campaign has been suspended by the first week of March 2020.

\section{Relevant results on the intermediate aircraft configuration}

The first experimental campaign was addressed to the estimation of both longitudinal and directional stability characteristics of the aircraft configuration drafted at the end of the first loop of design in the year 2017. This campaign was focused on assessing the aerodynamic effects of canard on wing and horizontal tail, with the aim to validate numerical predictions that have driven the design of such an innovative aircraft towards a three lifting surface configuration. Tests were performed at the main subsonic wind tunnel facility of the Industrial Engineering Department of the University of Naples Federico II. The wind tunnel facility is a closed-return, low-speed wind tunnel, shown in Fig. 2. Its main characteristics are reported in Table 2. 
For the measurement of the aerodynamic forces two tri-axial internal balances have been used, also supporting the model in the test section. For the longitudinal tests, the strain-gauge balance, has been used to measure lift, drag, and the pitching moment. It is made of $\mathrm{Al} 2024-\mathrm{T} 3$ with an estimated accuracy of $0.1 \%$ full scale. The entire assembly is mounted on a tilting system located below the test section floor. The angle of attack has been measured with the monoaxial tilt sensor CrossBow CXLA01. For the lateral-directional tests a different strain-gage balance has been used to measure the total lateral force, yawing, and rolling moments. This latter is made of Al 2024-T3 with an estimated accuracy of $0.1 \%$ full scale. The angle of attack is held constant to a fixed value depending on the mounting angle of the balance sting, which for this investigation it has been set to zero. The sideslip angle is changed by rotating the entire assembly with a mechanism located below the test section floor and it is measured by a linear potentiometer with an accuracy of $0.1^{\circ}$ and a range from $-15^{\circ}$ to $25^{\circ}$. All the aerodynamic forces have been reduced to typical aerodynamic coefficients, assuming as reference parameters the test section dynamic pressure $q$, the wing mean aerodynamic chord $c$, span $b$, and area $S$, except where otherwise stated. The Reynolds number is also based on the wing chord $c$, it has an average value of $R e=315000$ assuming an average wind speed of about $35-38 \mathrm{~m} / \mathrm{s}$.

Table 2. Wind tunnel of the DII, main characteristics.

\begin{aligned} & \hline Value \\ & \hline Test cross-section dimensions $2.0 \mathrm{~m} \times 1.4 \mathrm{~m} \\ &$ Turbulence intensity $0.10 \% \\ &$ Max shaft power $150 \mathrm{KW} \\ &$ Max wind speed $50 \mathrm{~m} / \mathrm{s} \\ &$ Test wind speed $38 \mathrm{~m} / \mathrm{s} \\ &$\hline\end{aligned}

A preliminary wind tunnel model of the airplane has been manufactured in aluminum alloy, through CNC machining. The scale factor is 1:25. The model installed in the UNINA (University of Naples) Low-Speed Wind-Tunnel testsection is shown in Fig. 3. Experimental data have been corrected for the aerodynamic effects of a closed-return wind tunnel, according to Ref. [15]. Transition strips have been applied to force the flow transition at the leading edge of lifting surfaces and on the fuselage nose. Three layers of aluminum tape have been applied in a zig-zag shape for each strip on each aircraft component. This wind-tunnel test campaign has been fundamental to assess CFD calculations in power-off conditions to define the final aircraft layout. Several configurations have been tested in order to appreciate and evaluate the effects of the aircraft component interaction, some results are shown in Table 3 in terms of longitudinal stability derivatives, while in Table 4, the directional stability derivatives of several aircraft configurations are reported, highlighting the effects of the canard and of the angle of attack on the directional stability behavior of the aircraft.
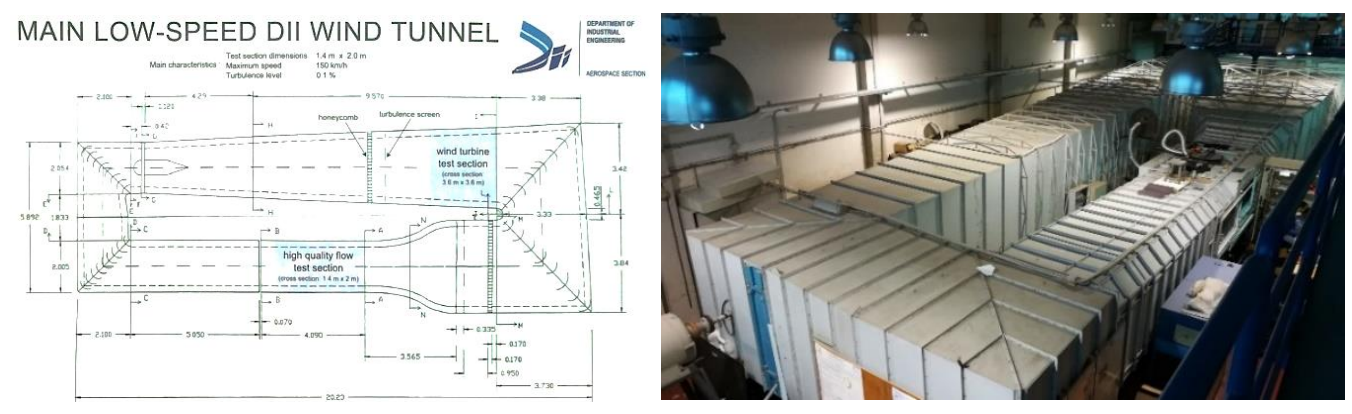

Fig. 2 Main subsonic wind tunnel of the Dept. of Industrial Engineering.

Table 3 Aircraft configurations and relevant aerodynamic characteristics: longitudinal derivatives.

\begin{tabular}{rrcc}
\hline Configuration & Symbol & Aero deriv. & Value \\
\hline Wing-body & WB & $C_{L \alpha}$ & $0.080 \mathrm{deg}^{-1}$ \\
Wing-winglet-body & WWB & $C_{L \alpha}$ & $0.087 \mathrm{deg}^{-1}$ \\
Wing-winglet-body-tail & WWBH & $C_{M C L}$ & -0.527 \\
Wing-winglet-body-tail-nacelle & WWBHN & $C_{M C L}$ & -0.395 \\
Wing-winglet-body-tail-nacelle-canard & WWBVHNC & $C_{M C L}$ & 0.065 \\
\hline
\end{tabular}




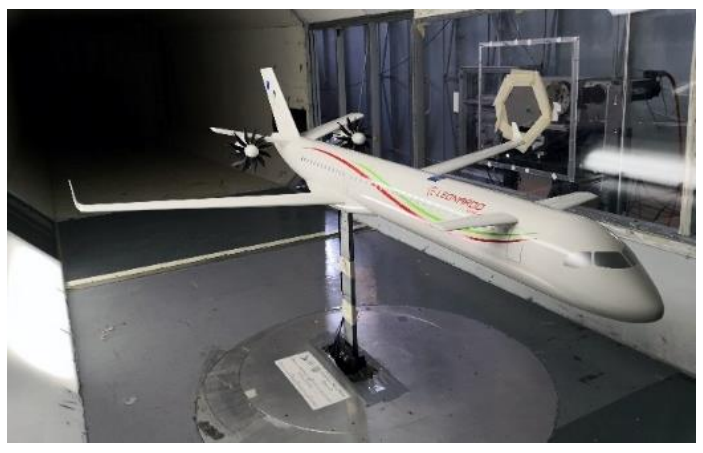

Fig. 3 The wind tunnel scaled model in the UNINA Low-Speed wind-tunnel test section.

Table 4 Aircraft configurations and relevant aerodynamic characteristics: directional derivatives.

\begin{tabular}{|c|c|c|c|c|}
\hline Configuration & Symbol & Der. & $\begin{array}{r}\text { Value }\left(\mathbf{d e g}^{-1}\right) \\
@ A o A=0^{\circ}\end{array}$ & $\begin{array}{l}\text { Value }\left(\mathrm{deg}^{-1}\right) \\
@ \text { AoA }=5^{\circ}\end{array}$ \\
\hline Body & B & $C_{N \beta}$ & -0.0022 & n.a. \\
\hline Body-Canard & $\mathrm{BC}$ & $C_{N \beta}$ & -0.0026 & n.a. \\
\hline Wing-Winglet-Body-Vtail & WWBV & $C_{N \beta}$ & 0.0020 & 0.0011 \\
\hline Wing-Winglet-Body-Htail-Vtail & WWBHV & $C_{N \beta}$ & 0.0021 & 0.0011 \\
\hline Wing-Winglet-Body-Htail-Vtail-Nacelle & WWBHVN & $C_{N \beta}$ & 0.0021 & n.a. \\
\hline Wing-Winglet-Body-Htail-Vtail-Canard & WWBHVNC & $C_{N \beta}$ & 0.0013 & 0.0000 \\
\hline
\end{tabular}

The reference point for the calculation of the aerodynamic moment coefficients is the leading edge of the mean aerodynamic chord (mac), which has been estimated to be a reliable maximum aft center of gravity position for this rear-engine aircraft configuration, see Ref. [1] [4]. Since the reference point is located at $0 \%$ mac, the neutral point will be equal to the stability derivative $\left(C_{M C L}\right)$ but opposite in sign.

Fig. 4 shows the comparison between the lift curve of wing-body (WB) and wing-winglet-body (WWB) configurations. The winglets increase the lift curve slope of about $+9 \%$, while their contribution in terms of longitudinal stability is almost negligible. The increase of the total wetted area, due to the winglets, leads to a friction drag increment of about 3 drag counts, as shown by the drag polar curves reported in Fig. 5. Despite the slightly increment of the minimum drag coefficient, winglets contribute to increase the induced drag factor by $15 \%$.

Another interesting result deals with the estimation of the detrimental effects of the nacelle installation. The aircraft configuration drafted at the beginning of a second loop of design, provided for the nacelle installation under the horizontal tail plane. Experimental results have highlighted a reduction of lift capabilities of the horizontal tailplane due to the nacelle aerodynamic interference, validating the numerical analyses shown by authors in Ref. [16]. Experimental data reported in Fig. 6 show a reduction in the stability derivative $C_{M C L}$ of about $13 \%$. The neutral point shifts from the $52 \%$ of the mac to the $39 \%$ of the mac, as reported in Table 3 .

The complete longitudinal aerodynamic behavior of such an innovative aircraft is shown in Fig. 7 and Fig. 8, where the lift coefficients versus the angle of attack and the pitching moment coefficients of the canard off and on configurations are compared, respectively. As it can be seen from chart of Fig. 8, the complete aircraft results to be longitudinally unstable, in fact the stability derivative $C_{M C L}$ is positive, as shown in Table 3 . The neutral point of the complete aircraft configuration lays at $-6.5 \%$ mac, being the considered center of gravity position placed at $0 \%$ mac.

It is worth to highlight that it makes no sense to directly compare the canard on and off configuration because the aircraft has been conceived as a three-lifting surface design. So that, the effect of the canard on the aircraft longitudinal stability, shown Fig. 8, does not have a dramatic impact on the aircraft design. The large static stability margin exhibited by the aircraft configuration without the canard is not a realistic value for such a design. As matter of fact, if such an innovative large turboprop configuration should be designed having only the wing and tail surfaces, it would be a completely different layout. The wing would have a larger area and it would be placed in a more advanced longitudinal position, the horizontal tail would be larger to face a completely different center of gravity excursion range, as authors have highlighted in Ref [1]-[4].

The focus of this experimental campaign has been the evaluation of the canard effects both the wing and the horizontal tail plane lift capabilities, to assess the numerical estimations that have driven the configuration design so far. By comparing the wing contribution for the configuration with and without the canard, significant effects due to 
the canard downwash and wake have been highlighted. It must be here remarked that the configuration tested in this first experimental campaign has no movable surfaces, thus, at this stage, it has been not possible to investigate the effects of the canard flap deflection on both wing and tail lift capabilities to assess the numerical results shown by authors in Ref. [5].

The most relevant effect of the canard, even in clean conditions, deals with a significant reduction of the horizontal tail plane lift capabilities. By comparing the horizontal tail contribution to lift and pitching moment for both canard on and off configurations, obtained by subtracting the values of configuration WWBHC and WWBH from the values of configuration WWBC and WWB, and shown in Fig. 9 and Fig. 10, respectively, it can be appreciated that the canard downwash reduces the lift curve slope of the horizontal tail of about $22 \%$, equally reducing the tail stabilizing contribution to the pitching moment coefficient of the whole aircraft. The large reduction of the tail contribution to the aircraft stability due to the canard downwash coupled to the detrimental effects of the nacelles installed under the horizontal tail plane, lead the aircraft to be longitudinally unstable, see Fig. 8.

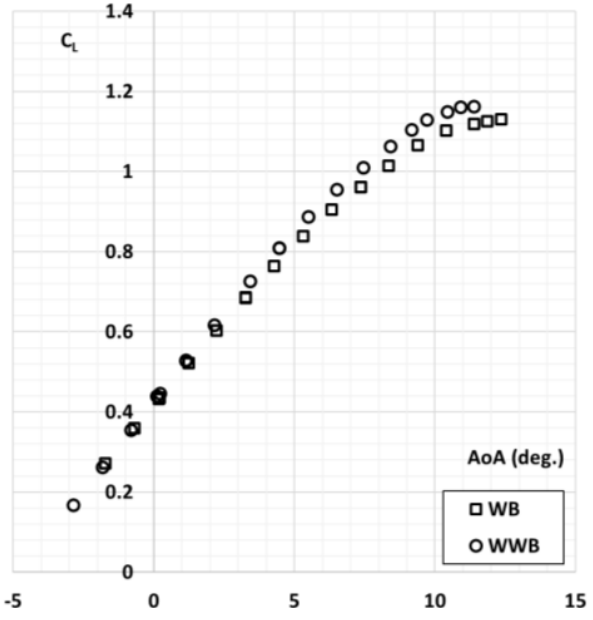

Fig. 4 Effect of the winglet on the wing-body lift coefficient. Loop 2 config. $R e=315000$.

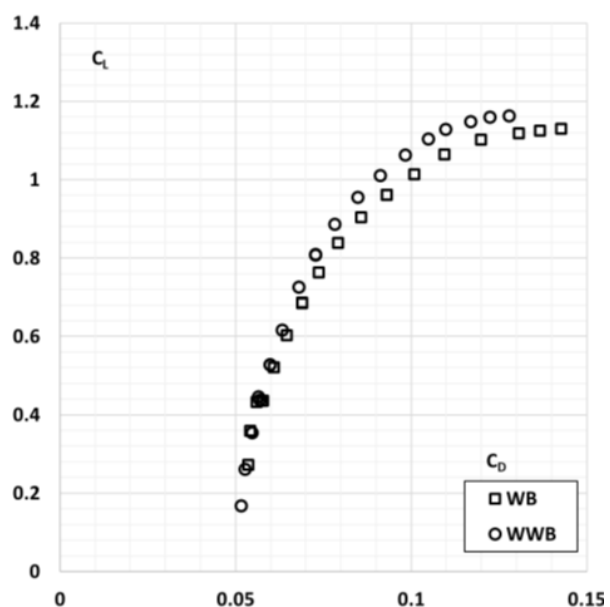

Fig. 5 Effect of the winglet on the wing-body drag polar. Loop 2 config. $R e=315000$.

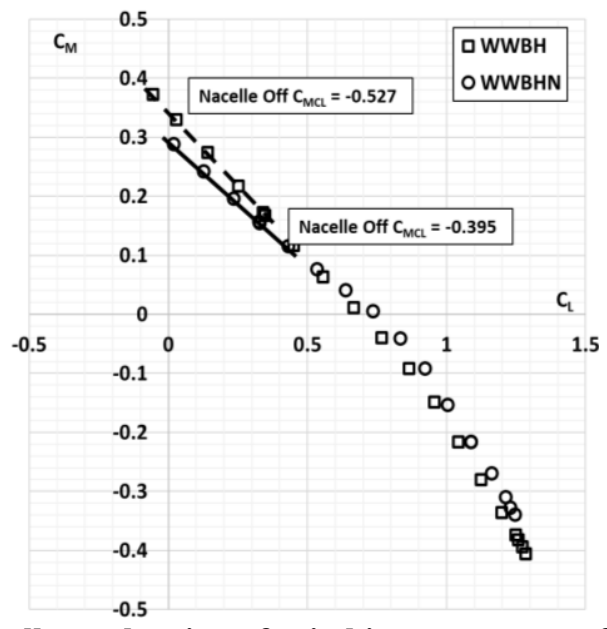

Fig. 6 Effect of the nacelle on the aircraft pitching moment coefficient, Loop 2 config. $\boldsymbol{R e}=\mathbf{3 1 5 0 0 0}$.

The collected data dealing with the longitudinal characteristics estimation through the first set of wind tunnel tests, helped the authors in refining the configuration by adjusting the horizontal tailplane area, its dihedral angle and by changing the engine installation form the under-tail position to the tail tip. Also, the canard vertical positioning has been revised, see Ref. [5]. Fig. 11 and Fig. 12 show the comparison between the initial loop 2 and the latest configuration. In particular, the canard has been shifted up (about $0.30 \mathrm{~m}$ in the full-scale aircraft) increasing the vertical stagger with respect to the horizontal tail. This latter has been re-designed, its dihedral angle has been reduced 
from 15 to 5 degrees and its span has been enlarged of about $3 \%$ with a slightly increase in the planform area (about 1\%). This has led to a higher tail aspect ratio, from 4.4 to 4.5. Moreover, thanks to the increased span, and despite the dihedral angle reduction, the required propeller ground clearance and aircraft upsweep angle at take-off rotation condition have been preserved thanks to the increased tail span. Fig. 13 and Fig. 14 show the back views of the loop 2 configuration and the revised geometry to better highlight differences in the tail design and canard positioning. Experimental results to validate the effectiveness of these design modifications are discussed in next sections

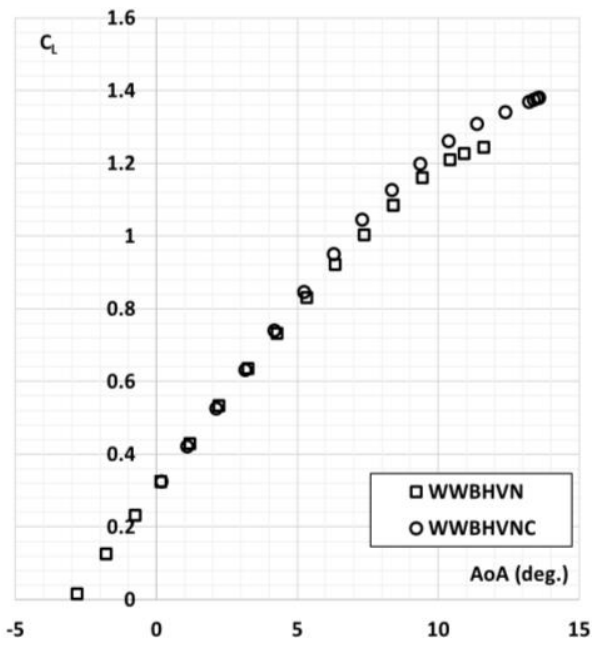

Fig. 7 Effect of the canard on the aircraft lift curve. Loop 2 config. $R e=315000$.

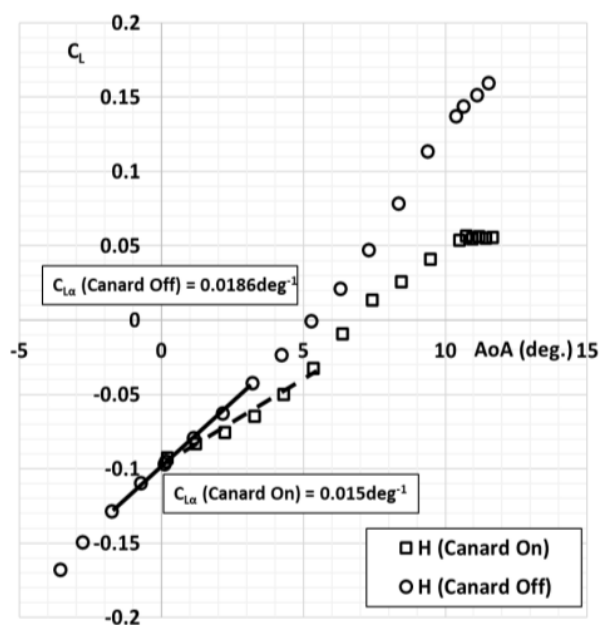

Fig. 9 Effect of the canard on tail lift coefficient, Loop 2 config. $R e=315000$.

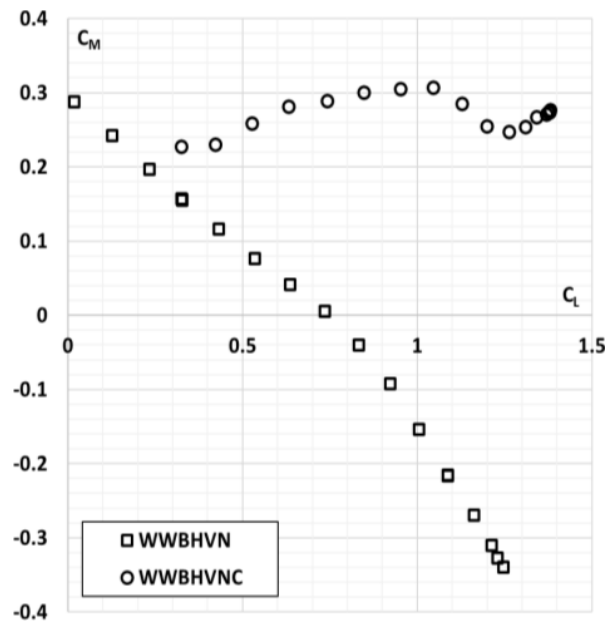

Fig. 8 Effect of the canard on the aircraft pitching moment coefficient, Loop 2 config. $R e=315000$.

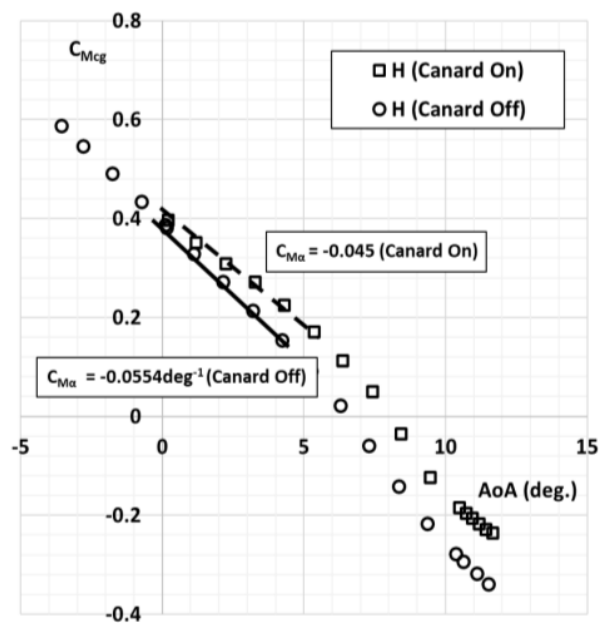

Fig. 10 Effect of the canard on tail pitching moment coefficient, Loop 2 config. $R e=315000$.

The experimental campaign on the loop 2 configuration has been also addressed to evaluating directional stability characteristics of the aircraft. In Fig. 15 the yawing moment coefficients of the isolated body and the body plus the canard are compared. As highlighted by the directional stability derivatives $\left(C_{N \beta}\right)$ in Table 4 , the canard increases the fuselage unstable contribution to the aircraft directional stability of about $14 \%$. This is the typical effect of high wing configurations, in which the wing surface creates a high-pressure region on the windward fuselage side. In this case this effect is magnified because of the longitudinal position of the canard which is placed quite forward the fuselage center of gravity. 


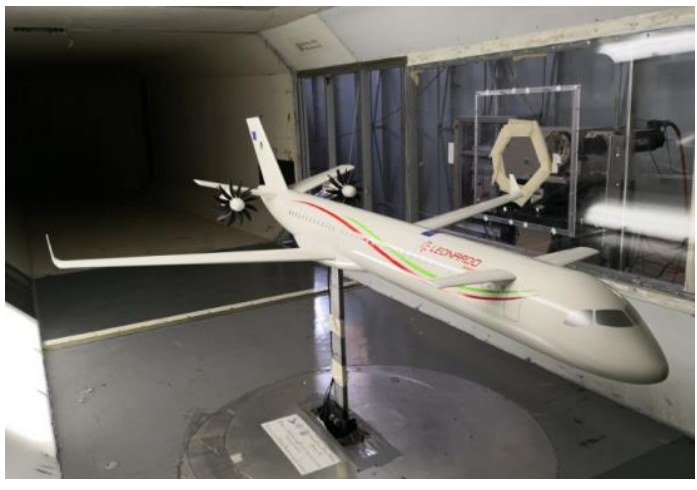

Fig. 11 Initial loop 2 aircraft configuration.

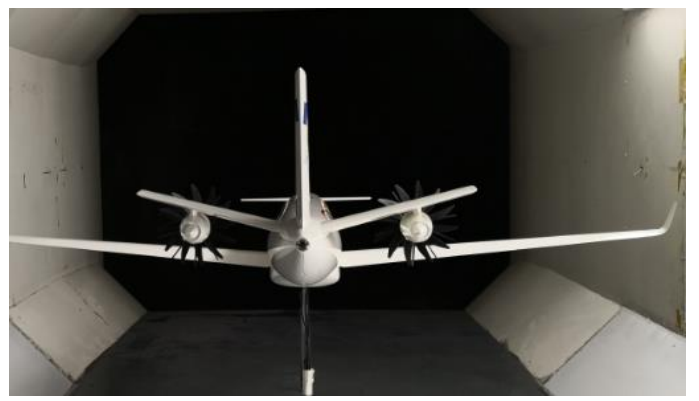

Fig. 13 Loop 2 aircraft configuration, back view.

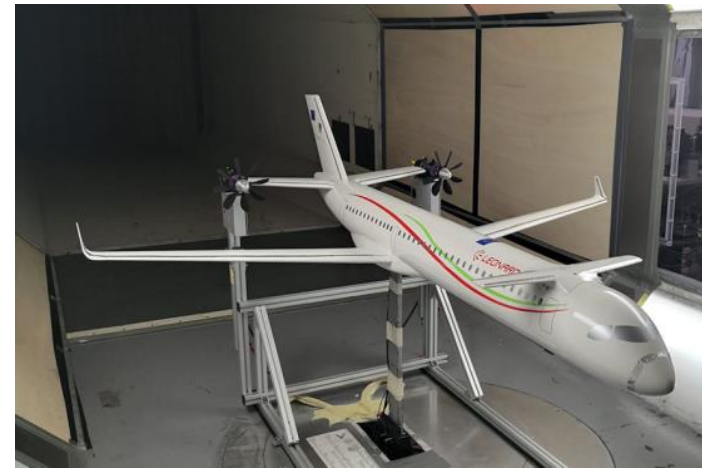

Fig. 12 Latest aircraft configuration.

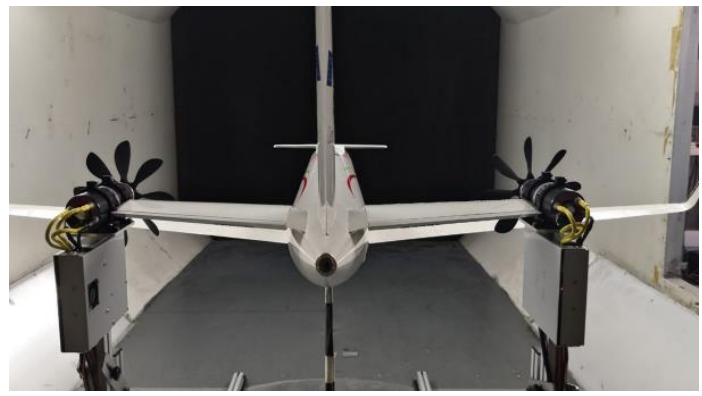

Fig. 14 Latest aircraft configuration, back view.

The horizontal tail leads to an increment of about $5 \%$ of the overall aircraft $C_{N \beta}$, see Fig. 16. This contribution can be appreciated by comparing the $C_{N \beta}$ of the canard-off configuration with and without the horizontal summarized in Table 4. This advantageous interference effect is known from literature [9][10][19].

Tests with and without nacelles have highlighted that they do not affect the directional capabilities of the aircraft as shown in Table 3. Same results have been achieved with winglets, which affect in a sensible way the lateral stability.

The complete aircraft $C_{N \beta}$ in the canard-off configuration is about $0.0021 \mathrm{deg}^{-1}$, see Table 4 . The full-scale vertical tail has a planform area equal to $25.4 \mathrm{~m}^{2}$, but the generated directional stability is almost half of the value that it should achieve accordingly with its size. This is due to the original untapered, swept planform, providing for a constant sweep angle of $45^{\circ}$ at any chord station, significantly lowering the empennage lift capabilities, accordingly with the Diederich formula, see Ref. [18].

Directional stability at increasing angles of attack is presented in Fig. 17 where the yawing moment coefficients of the WWBV configuration at $0^{\circ}$ and $+5^{\circ}$ angles of attack are compared. It is well known, see Ref. [19], that when the angle of attack increases the vertical tail effectiveness is lowered because of the fuselage wake impinging on the empennage. By looking at Table $4, C_{N \beta}$ is almost halved. It is here remarked that the experimental data are related to a low Reynolds number, this means that the effects of the angle of attack dealing with the fuselage boundary layer thickness could be overestimated.

The most detrimental effect on the directional stability is introduced by the canard surface. As it is shown in Fig. 18 and reported in Table 4, the canard reduces the directional stability derivatives by $38 \%$ at zero angle of attack. The combined effects of incidence angle and canard lead to a dramatic reduction of the directional stability, the aircraft even become directionally unstable when the angle of attack is higher than $5^{\circ}$. This strong effect is introduced by the vortex system which is impinging on the vertical empennage (see Fig. 19 and Fig. 20). All these experimental data and considerations have been used to redesign the vertical tailplane.

To solve the lack in the aircraft directional stability due to the initial vertical tail plane planform and to compensate the negative effects of the angle of attack (magnified by the canard wake at the tail), the vertical surface has been completely redesigned, taper ratio has been modified to reduce the sweep angle at the middle point of the mean aerodynamic chord and the planform area has been increased by $6 \%$. 


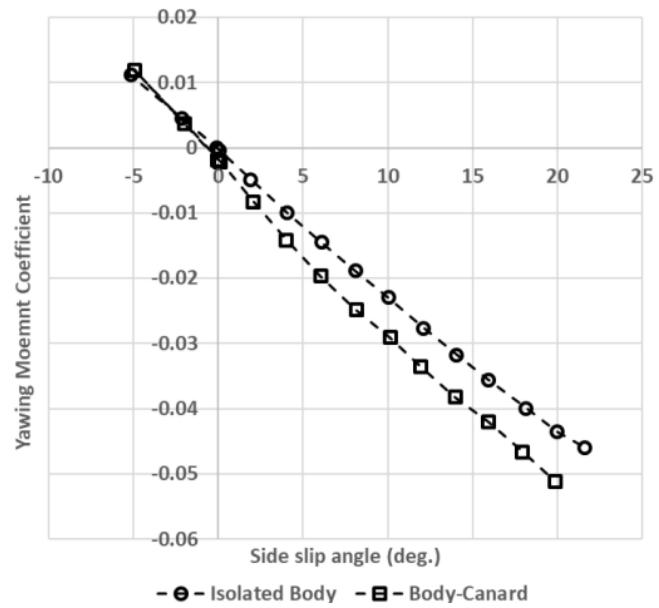

Fig. 15 Effect of the canard on the fuselage yawing moment coefficient. Loop 2 config. $R e=315000$.

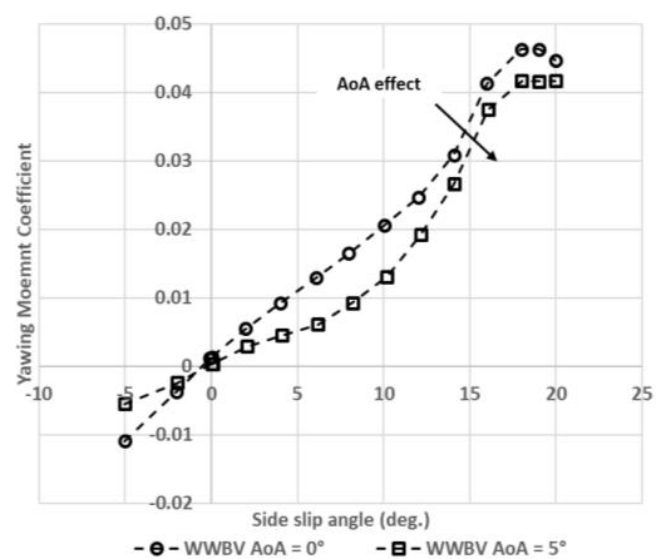

Fig. 17 Effect of the angle of attack on yawing moment coeff. Loop 2 config. $R e=315000$.

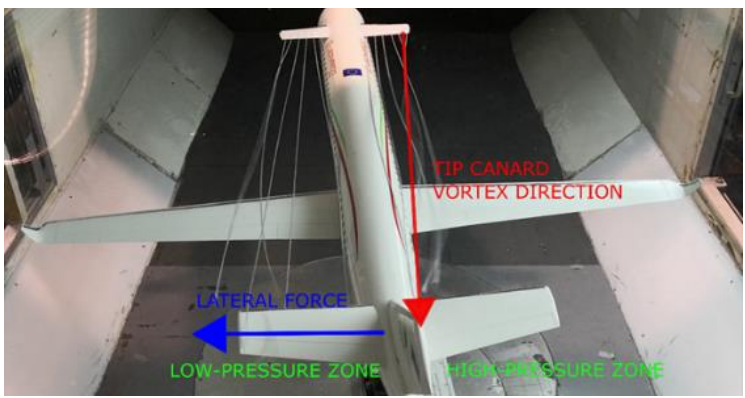

Fig. 19 Flow visualization with tufts rake, $\beta=8^{\circ}$.

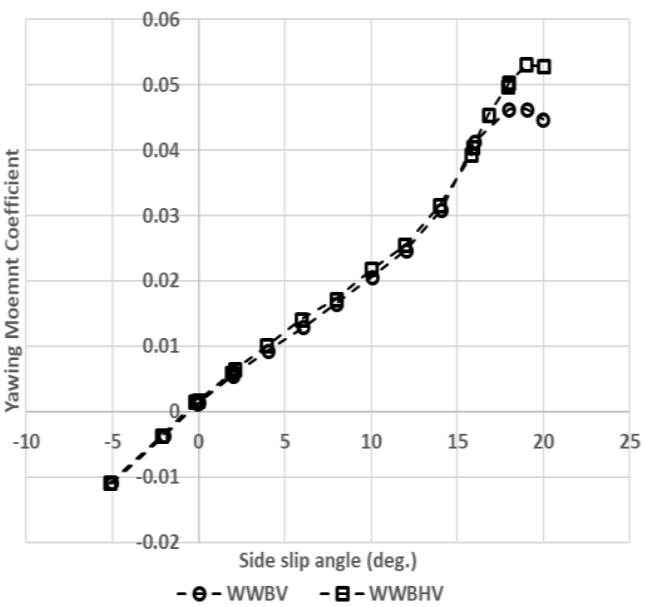

Fig. 16 Effect of the horizontal tail on yawing moment coefficient. Loop 2 config. $R e=315000$.

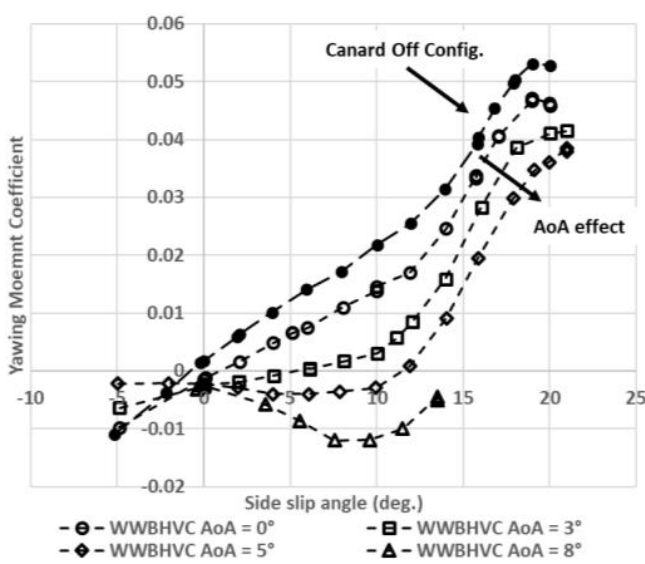

Fig. 18 Combined effect of canard and angle of attack on yawing moment coeff. Loop 2 config. $R e=315000$.

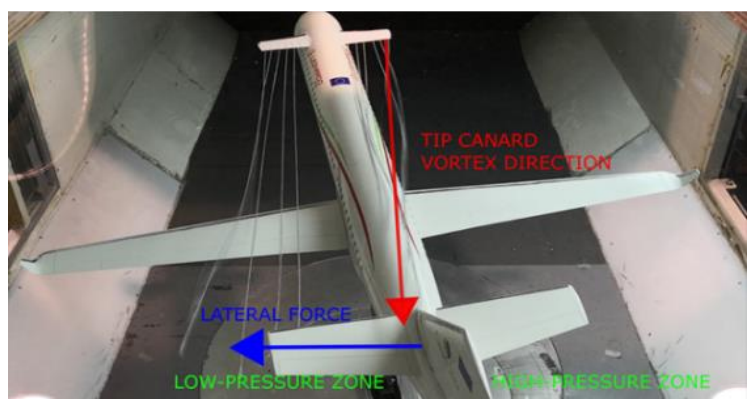

Fig. 20 Flow visualization with tufts rake, $\beta=10^{\circ}$.

Fig. 21 shows a CAD drawing comparing the initial vertical tail plane design with the latest one, whereas Fig. 22 shows the updated vertical tail plane geometry installed on the latest scaled model in the wind tunnel section. 


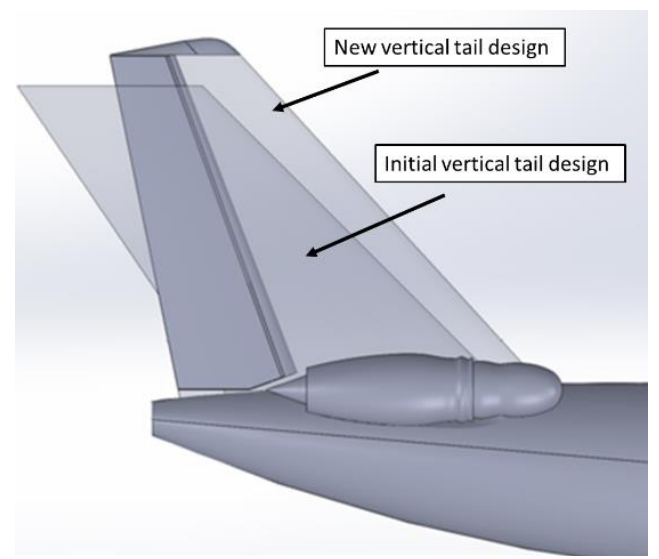

Fig. 21 Vertical tail and rudder re-design, CAD drawing.

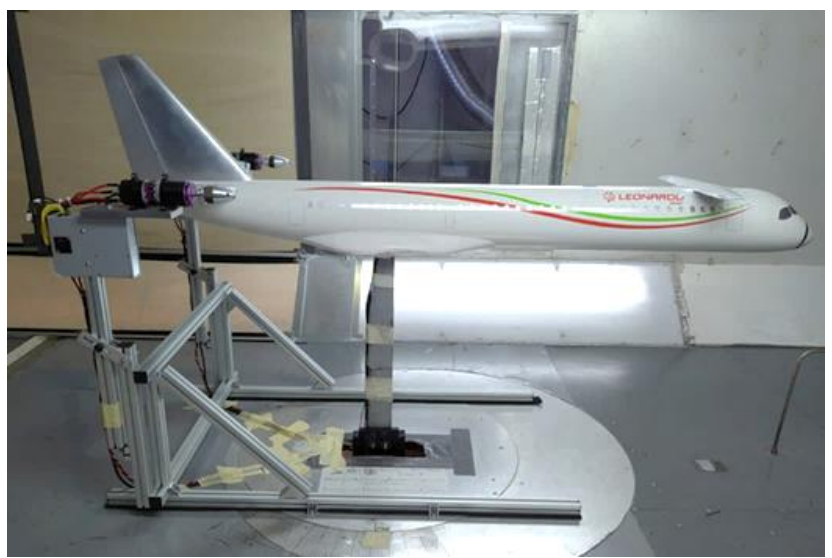

Fig. 22 Latest aircraft configuration: detail of the scaled model vertical tail plane.

\section{Latest Aircraft Configuration and propulsive system scaling}

With the results collected during the first loop of design and the wind tunnel test campaign accomplished on an intermediate aircraft configuration, the final aircraft layout has been defined. Thus, a new scaled model has been designed and manufactured. Starting from the available test article, the fuselage has been kept unchanged, while all the lifting surfaces have been manufactured again and equipped with their relative movables.

In Fig. 23 a rendering and a picture of the last aircraft configuration are presented. The engine nacelles are now installed at the horizontal tail tip. The new scaled model is equipped with all movables, their deflections matrix is summarized in Table 5.

Table 5 Updated test article available movables deflections.

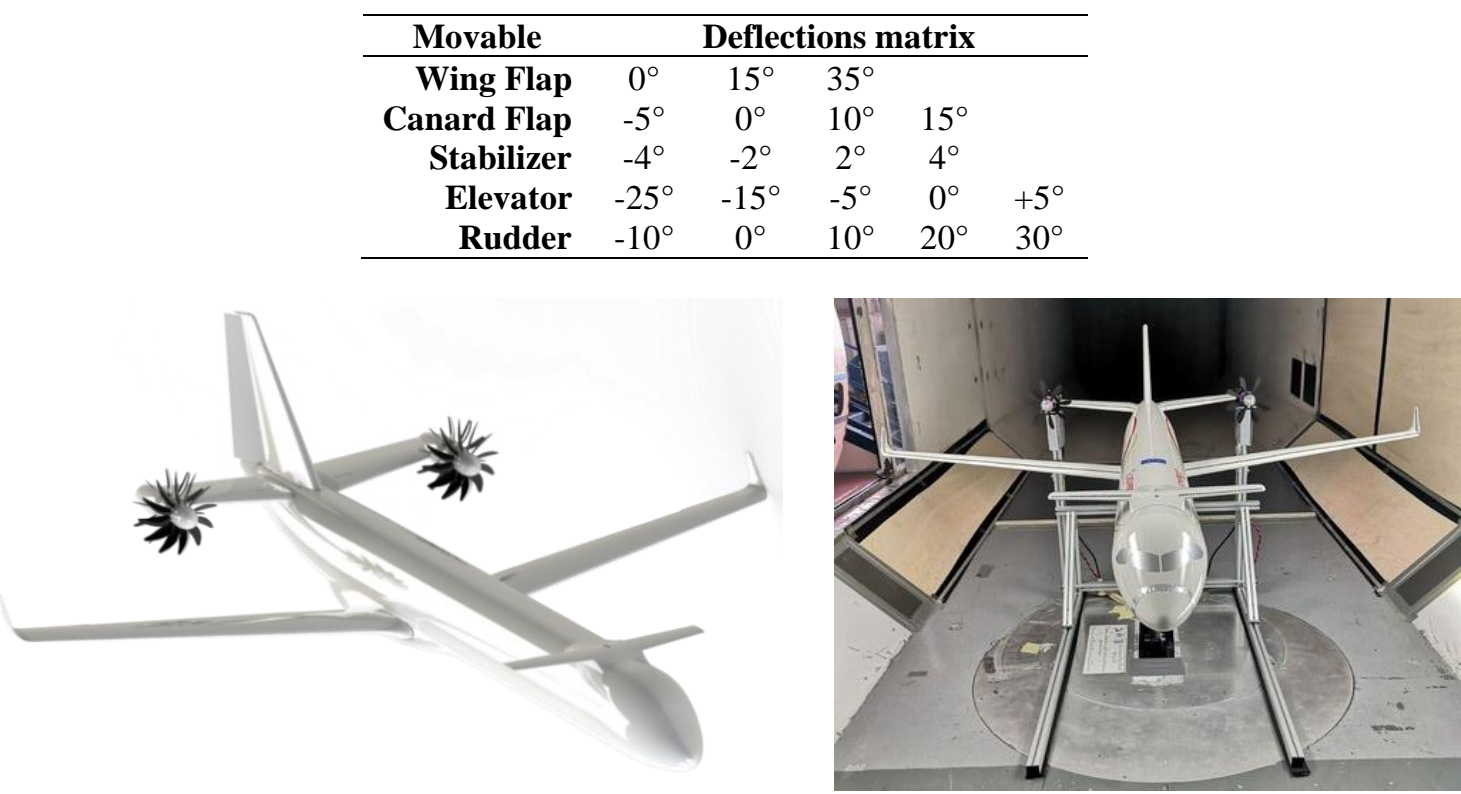

Fig. 23 Latest aircraft configuration.

The 1:25 scale of the aircraft model and the wind tunnel operating speed determined the scale of the propulsive system. The engine deck provided by GE Avio has been scaled by applying the thrust similarity, a principle stating that both the model and full-scale propeller have the same coefficients:

$$
J=\frac{V_{\infty}}{n D}
$$




$$
\begin{aligned}
& C_{T}=\frac{T}{\rho n^{2} D^{4}} \\
& C_{P}=\frac{P}{\rho n^{3} D^{5}}
\end{aligned}
$$

representing the propeller advance ratio (Eq. 1), thrust coefficient (Eq. 2) and power coefficient (Eq. 3). The complete thrust similarity is achieved by matching both $C_{T}$ and $C_{P}$. This is quite difficult to fulfil, since even with an identical, scaled copy of the real propeller, which geometry at time of writing is unknown, the smaller Reynolds number attainable in the wind tunnel limits the maximum values of such coefficients [15][20]-[23]. Moreover, in a wind tunnel test the flow speed $V_{\infty}$ is usually kept constant, limited only by the maximum power available to the fan or the maximum load tolerated by the strain gage balance. Consequently, the desired advance ratio $J$ is obtained by varying the propeller RPM. For these reasons, the axial and rotational flow speeds are scaled differently: at the same thrust coefficient $C_{T}$ the swirl of the scaled propeller will be different from that generated by the full-scale propeller, hence the power coefficient $C_{P}$ will be different. As the objective of the wind tunnel test campaign is the evaluation of propulsive effects on aircraft stability and control characteristics, the authors decided to attempt to match the thrust coefficient $C_{T}$ for a few representative flight conditions.

The theory of aircraft stability and control [24] states that propulsive effects can be divided into direct and indirect effects. Direct effects are due to the aerodynamic forces exerted by and on the propeller: the thrust $T$ and the normal force $N$. The last is orthogonal to the thrust line and it is generated in non-axial flows. Both produce a pitching moment which value depends on the distance of the aircraft centre of gravity to the thrust line and propeller disk. Indirect effects are related to the propeller slipstream impacting on the tailplane, altering the downwash and sidewash angles, and on the variation of dynamic pressure at the tailplane due to the pressure jump through the propeller disk.

In the IRON innovative aircraft configuration, the motors and propellers are mounted on the horizontal tailplane tips. The following effects are expected:

- $\quad$ asymmetric thrust distribution due to wing and canard wakes impinging on propellers' disks

- horizontal tailplane lift varying with propeller load due to the flow swirl inducing vertical velocities at tailplane

- different propellers thrust and normal force, even with identical propulsive units, due to the abovementioned aerodynamic effects.

The previous effects are qualitatively illustrated in Fig. 24.

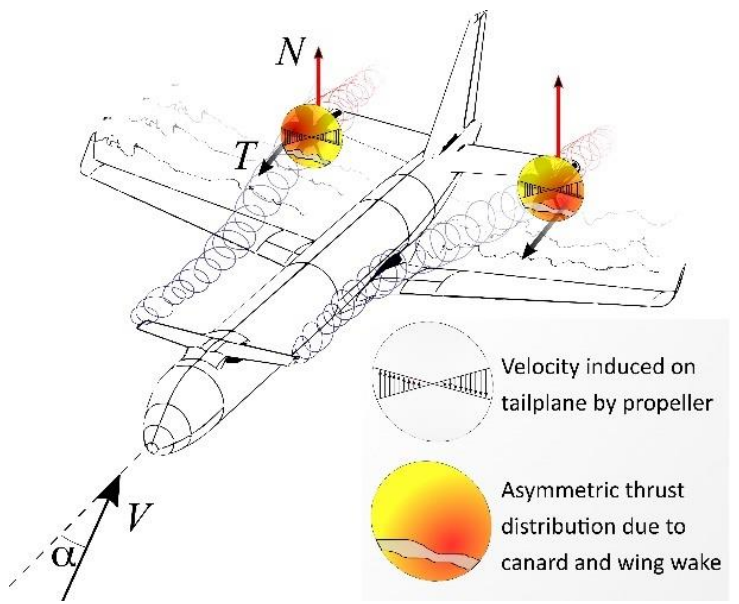

Fig. 24 Illustration of aero-propulsive interactions on the IRON innovative aircraft.

From the original engine deck provided by GE Avio, the selected flight condition to be reproduced in the wind tunnel is the max climb (MXCL). From this condition the model's scale and wind tunnel settings, as well as the scaled engine torque, power, and RPM are derived. These are used to select a motor drive as a component off-the-shelf.

As scaled engine an electric motor has been chosen, because of the high scalability, availability, versatility, and safety of such a machine. Each motor has its own characteristics as operating voltage and current per torque load. These require the sizing of the power, acquisition, and control system. Similarly, with the assigned flight condition, propeller coefficients and diameter, the scaled propeller has been designed. 
The selected electric motor is the Lehner 2280/40 LK. The manufacturer provides performance tables at constant voltage. Each table lists absorbed current, input power, RPM, torque, output (shaft) power, and efficiency. It resulted that this motor has a constant $K_{v}=185 \mathrm{Volt} / \mathrm{RPM}$, ideal for relatively high torques and low speeds. Several performance tables have been collected and processed with MATLAB ${ }^{\circledR}$ to generate motor maps. The classic torque versus RPM map with motor's efficiency contour is shown in Fig. 25. Any propeller operating point falling within this map is reproducible in the wind tunnel since these combinations of torque load and RPM are within the motor's limits. This chart has been useful to size the power system.

For the selected flight conditions, no available RC propeller seemed to be fit for the expected torque loads and RPM. Therefore, a propeller for the MXCL condition has been designed. It is quite challenging to achieve both high thrust coefficient and efficiency, because of the low Reynolds number (less than 100000) of the scaled propeller with $14.6 \mathrm{~cm}$ diameter. XROTOR has been chosen as design software, since it is believed to be the best propeller design package available to the public, especially if accurate section data are loaded [25].

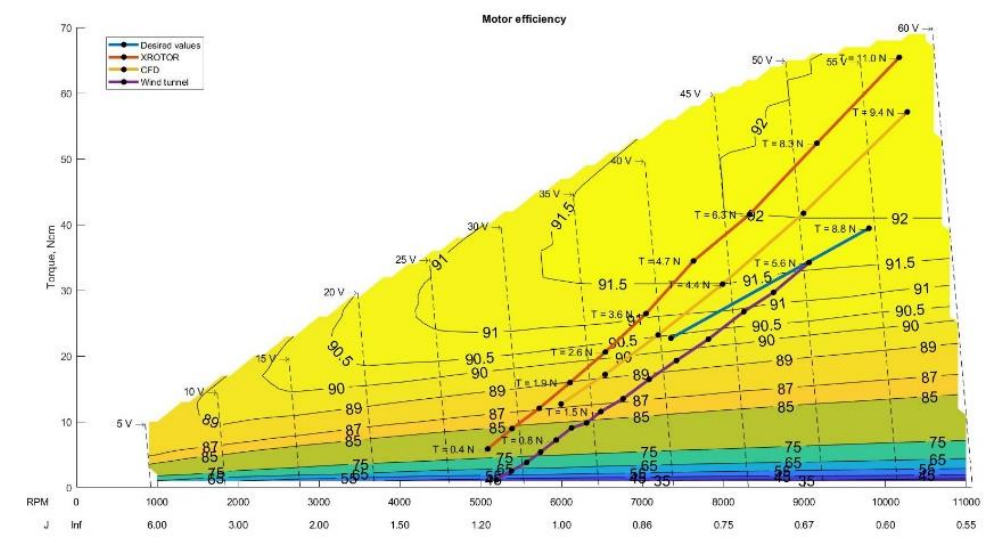

Fig. 25 Lehner 2280/40 motor map with propeller operating points.

The design workflow starts from design requirements (diameter, RPM, power or thrust), the blade is designed with XROTOR aiming for minimum induced loss for a given operating point. Then, the propeller is analyzed on a range of advance ratios. If the performance is inadequate, an optimization loop on the blade section may be performed with XFOIL and MATLAB ${ }^{\circledR}$. At the end of the aerodynamic design, a simple structural analysis checks if the blade is strong enough for the expected aerodynamic and centrifugal loads, otherwise it is suggested to increase the blade thickness and the workflow goes back to the design routine. At the end of the design process, a high-fidelity CAD is semi-automatically generated. This 3D geometry is ready for advanced numerical analyses and manufacturing.

As concern the blade section, several typical propeller airfoils have been analyzed. The MATLAB ${ }^{\circledR}$ routine has been run to perform a single objective optimization, aiming to minimize drag at the desired blade lift coefficient. The airfoil is parameterized with the PARSEC technique [26] and it is optimized with a genetic or a particle swarm algorithm, where XFOIL is called on parallel workers to perform viscous analyses at the selected Reynolds number and lift coefficient. The optimized propeller must be feasible to manufacture and to operate. The typical optimization output provided a rear shape that may result too fragile for the application. Therefore, the SDA 1075 airfoil [22] has been chosen, blending it with a circular section at hub to increase structural stiffness.

RANS analyses have been performed with STAR-CCM+ at the end of the design process. The propeller rotation is simulated with the moving reference frame technique. The flow field is stationary, fully turbulent $(k-\omega$ model), discretized with more than 7 million polyhedral cells for an eight-bladed rotor (Fig. 26). Being interested only in propeller thrust, torque, power, and their relative coefficients, propeller rotation has been simulated with the moving reference frame technique of STAR-CCM+ in a stationary flow regime [27].

As XROTOR may underpredict thrust by 10\% [25], after several design iterations it was chosen to aim at $110 \%$ of the desired thrust to get satisfactory performance. Fig. 27a-b show the thrust and power coefficients of the propeller designed for the MXCL condition with data predicted by XROTOR (blue line), CFD (yellow line) and the target values (grey line). The desired $C_{T}$ values are between CFD and XROTOR results, whereas the desired $C_{P}$ values are always lower. As expected, the max efficiency calculated with both tools is lower than desired, about 0.2 for the CFD data (Fig. 27c). 

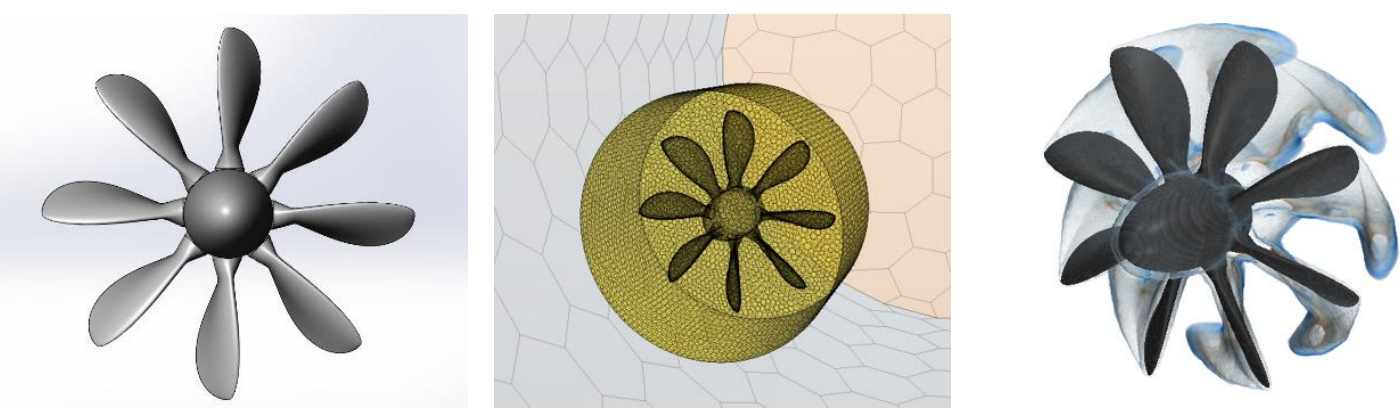

Fig. 26 Propeller CFD RANS validation.

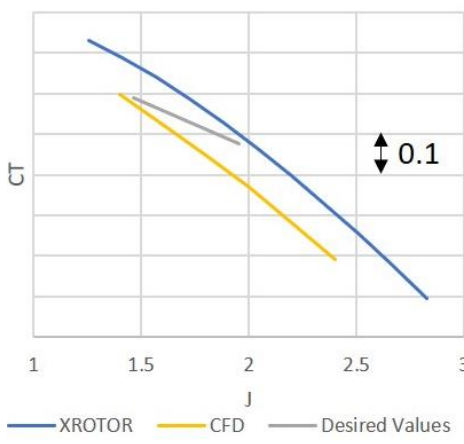

(a)

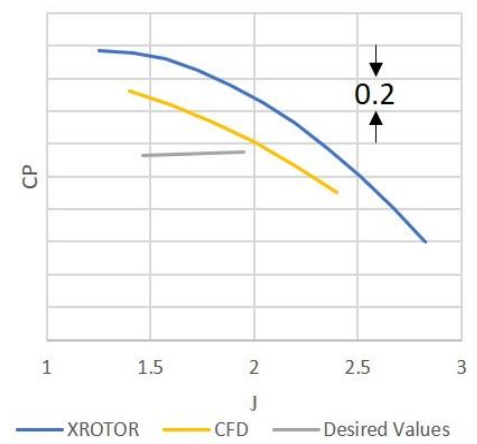

(b)

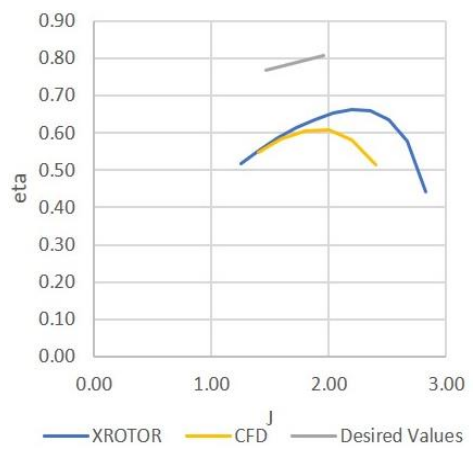

(c)

Fig. 27 Propeller analysis: (a) thrust coefficient; (b) power coefficient; (c) efficiency.

The power supply, data acquisition and motor control scheme are shown in Fig. 28. The propulsive system has been instrumented with a frame of two orthogonal load cells to measure propeller thrust and normal force (10 Kgf range, $0.1 \%$ accuracy), a temperature sensor to monitor the motor's temperature during operations, an optical RPM counter installed on the rear shaft, and an electronic speed controller (ESC) MGM Compro HBC series (air cooled). Data acquisition and motor control has been performed by a National Instruments ${ }^{\mathrm{TM}}$ USB-6341 card. Power supply has been provided by four $12 \mathrm{~V}, 54 \mathrm{Ah}$ lead batteries, generating a constant voltage for a reasonable amount of time and absorbing power in the case of propeller braking.

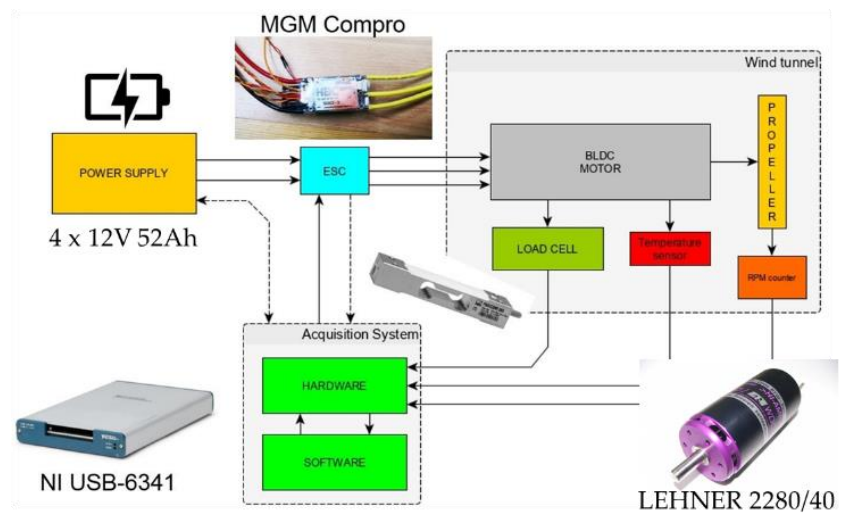

(a)

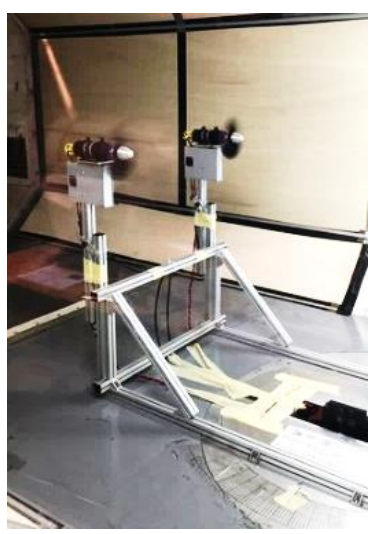

(b)

Fig. 28 (a) Data acquisition and control scheme; (b) motor support stand.

The motor support system, manually operated with wind tunnel turned off, is designed to move the motors in the correct position near the aircraft, without contact, to directly measure propeller thrust and normal force. It provides clamps for the motors as well as housing for the ESC and the load cells. The motor can be moved along three axes and rotated about the local pitch axis, following the different attitudes of the aircraft. 
Motor torque is not directly measured but calculated from the electric power drained from the battery and the motor electric efficiency values interpolated from manufacturer data for each operating condition. Electric current and voltage are transduced into an analog signal measured by the data acquisition system.

\section{Relevant experimental results on the latest aircraft configuration, including propulsive effects}

Validation of the design has been performed in the wind tunnel running at $35 \mathrm{~m} / \mathrm{s}$ (design speed for the scaled MXCL condition) and the results are shown in Fig. 29 for the isolated propeller installation. It is here remarked that the propeller thrust has been measured by a load cell, the net thrust shown in the chart has been obtained by subtracting the drag of the motor frame from the measured axial force, and the propeller torque has been calculated from the absorbed electric power, since no torque meter has been installed. This may explain the shift in the shaft power curve calculated with RANS with respect to the experimental data, whereas the thrust curve obtained by CFD is overlapped to the wind tunnel data.

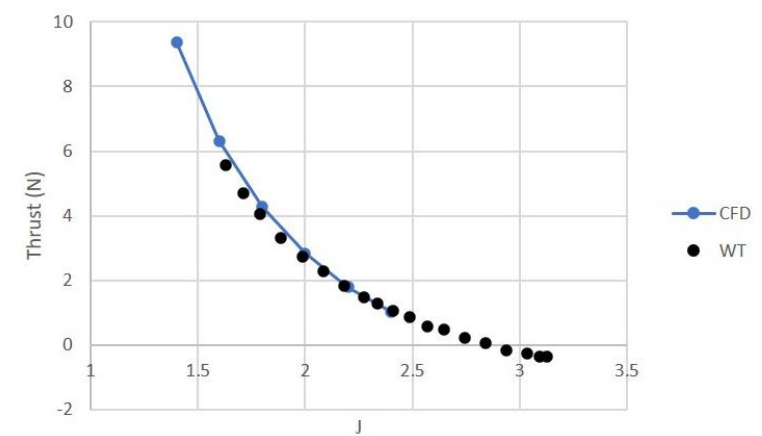

(a)

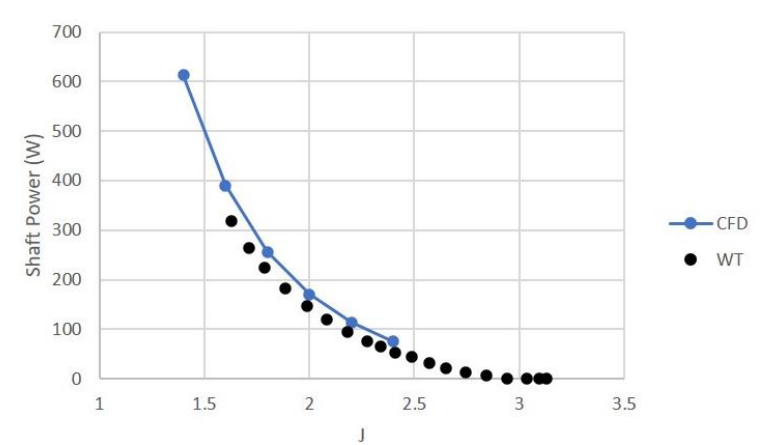

(b)

Fig. 29 Validation of propeller design: (a) thrust; (b) power. Isolated propeller installation.

Once the validation of the propeller design has been carried out, the aircraft model described in Sec. IV has been tested in order to estimate the effectiveness of geometry modifications suggested by the outcomes of the first tests campaign (see Fig. 30). It is worth to underline that the propulsive system, including the force load cells, is isolated from the aircraft model and therefore the thrust and normal forces due to propulsive system are decoupled with respect to the aerodynamic ones. In this way, the model strain gauge balance measures only propulsive indirect effects (i.e. propeller slipstream) on aircraft stability and control. Direct effects due to propeller thrust and normal force are added later.

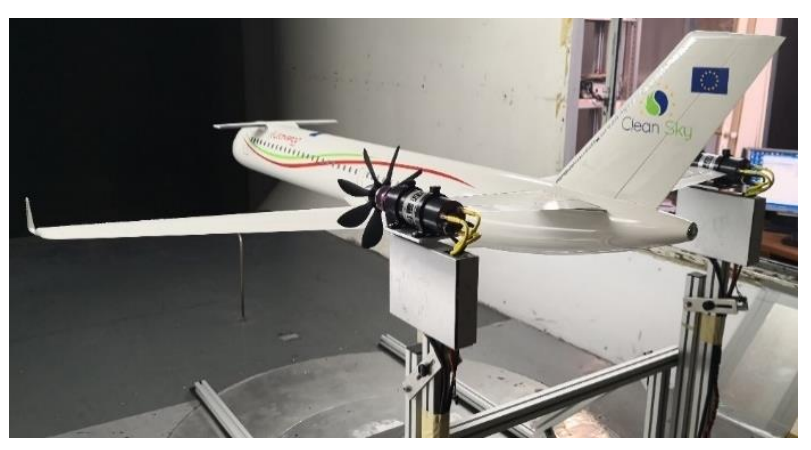

Fig. 30 Latest aircraft model with propeller in the wind tunnel.

As already stated above, the objective of the wind tunnel test campaign is the evaluation of propulsive effects on aircraft stability characteristics. Therefore, it has been decided to attempt to match the thrust coefficient $C_{T}$ for a few representative operating conditions. In greater detail, two operating points (RPM) corresponding to MXCL climb condition have been selected, as reported in Table 6.

The modifications made to the horizontal tail plane have led to an increase of its effective aspect ratio of and planform area. Consequently, the contribution of the tailplane to the global pitching moment ensures the stability of the aircraft even at low attitude, which has been detected as one of the main issues of the initial loop 2 configuration, as shown in Fig. 31. Experimental tests have demonstrated the beneficial propulsive effects on longitudinal stability 
with an increment of derivative $C_{M C L}$. As a matter of fact, the estimated curve slope is equal to $25 \%$ for power-on condition, versus a $17 \%$ related to power-off condition.

Table 6 Summary of the tests performed, $\mathrm{Re}=\mathbf{3 1 5 0 0 0}$.

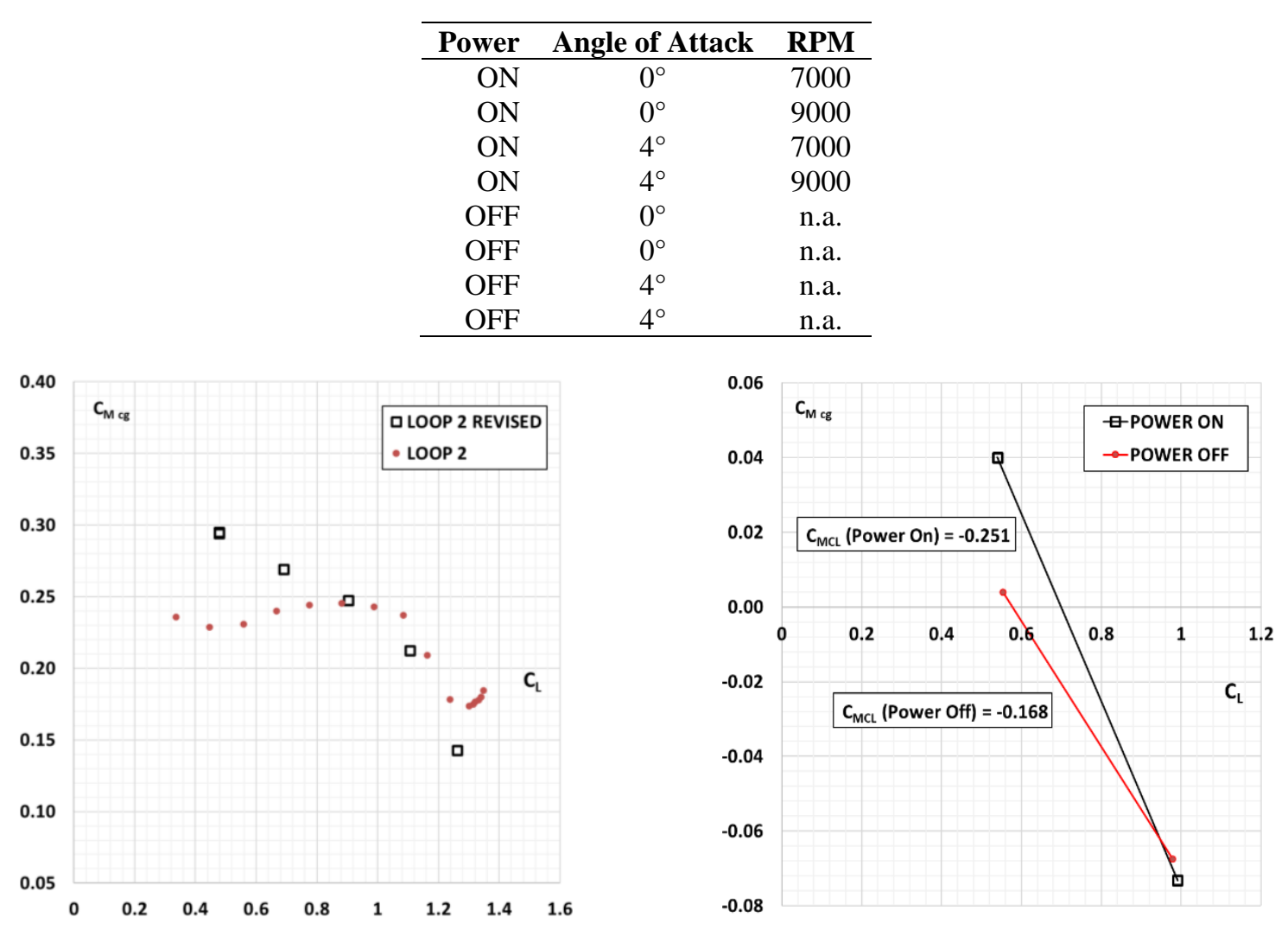

Fig. 31 Effect of tailplane geometry changes on Fig. 32 Longitudinal stability curves for power-on stability curve, experimental results, power-off $(J=1.7)$ and power-off configurations. Complete condition. Pitching moment computed with respect aircraft configuration with $i_{H}=4$ deg, pitching to maximum aft CG position, $R e=315000$ (both moment computed with respect to maximum aft CG configurations are without nacelles). position, $R e=315000$.

As expected, the predicted enhancement of longitudinal stability is due to the direct propulsive effects, since the propeller disk is positioned higher than the CG, and because of indirect effects due to higher wind speeds downstream the propeller produced by to the pressure jump across the propeller disk.

As reported in Fig. 32, results shown a shift of the pitching moment coefficient curve and more negative slope for the power-on case. The offset is a combination of the nose down pitching moment due to the high propeller location and a change in load on the horizontal tailplane. The pitching moment contribution due to thrust (direct effect) is not depending on angle of attack unlike the other two contributions (indirect effects), which are more intense as the angle increases.

\section{Conclusion}

The aerodynamic characteristics of an innovative high capacity turboprop aircraft have been assessed by means of a wind tunnel test campaign on a 1:25 scaled model. The experimental tests performed on the initial loop 2 configuration have contributed to assess the aerodynamic behavior of such an innovative large turboprop platform developed within the IRON project. Tests have been conducted to estimate both beneficial and detrimental effects of a third lifting surface installed in front of the main wing. The research work presented in this paper, has highlighted the effects on longitudinal as well as on the directional stability introduced by the canard wake interaction with tail planes. The achieved experimental results have driven the re-design of aircraft tail planes and canard positioning. 
These modifications aimed at mitigating the detrimental effects due to the strong aerodynamic coupling introduced by the reduced vertical stagger between the lifting surfaces in a such aircraft configuration.

Once the final aircraft layout has been assessed, a second wind tunnel test campaign has been performed, including the estimation of the propulsive effects on the aircraft aerodynamic behavior. Unfortunately, the health emergency due to the Coronavirus (COVID-19) outbreak has prevented the completion of the whole scheduled experimental campaign. Thus, this paper has shown only few significant results dealing with the longitudinal stability estimation of the complete aircraft with and without the propulsive effects. Anyway, the few performed experimental tests have highlighted the effectiveness of the modifications made at the aircraft layout concerning the longitudinal stability and have highlighted the effects of the propeller blowing on the tail plane.

Once the wind tunnel tests campaign will be finally accomplished, the authors reserve the right to disseminate a comprehensive overview of all the achieved results in further works.

\section{Acknowledgments}

The IRON project has received funding from the Clean Sky 2 Joint Undertaking under the European Union's Horizon 2020 research and innovation program under Grant Agreement $n^{\circ}$ 699715. In particular IRON project is part of Clean Sky 2 REG-GAM 2018 project implemented on the H2020 program under GA 807089. The authors are grateful to the partners of the IRON consortium for their contributions and feedback. The content of this paper reflects only the author's view and both the European Commission and the Clean Sky 2 Joint Undertaking are not responsible for any use that may be made of the information it contains.

\section{References}

[1] S. Corcione, V. Trifari, F. Nicolosi, V. Cusati, D. Ciliberti, P. Della Vecchia, "Feasibility study of innovative regional turboprop: an overview of the European project IRON," MATEC Web Conf. 304 03014, 2019. doi: 10.1051/matecconf/201930403014

[2] F. Nicolosi, S. Corcione, V. Trifari, V. Cusati, M. Ruocco, P. Della Vecchia, "Performance Evaluation and DOC Estimation of an Innovative Turboprop Configuration," Aviation Technology, Integration, and Operations Conference, 2018. doi: $10.2514 / 6.2018-3662$

[3] F. Nicolosi, S. Corcione, P. Della Vecchia, V. Trifari, M. Ruocco, "Aerodynamic Design and Analysis of an Innovative Regional Turboprop Configuration," 31st International Council of the Aeronautical Sciences, ICAS, 2018, ISBN: 978393218288-4. doi: 2-s2.0-85060462588

[4] F. Nicolosi, S. Corcione, V. Trifari, P. Della Vecchia, A. De Marco, "Design Guidelines for High Capacity Innovative Regional Turboprop Aircraft," AIAA Scitech 2019 Forum, 2019. doi: 10.2514/6.2019-0256

[5] S. Corcione, F. Nicolosi, P. Della Vecchia, D. Ciliberti, V. Cusati, "High Lift Aerodynamic Characteristics of a Three Lifting Surfaces Turboprop Aircraft," AIAA Aviation 2019 Forum, 2019. doi: 10.2514/6.2019-2884

[6] V. Cusati, F. Nicolosi, S. Corcione, D. Ciliberti, P. Della Vecchia, "Longitudinal stability issues including propulsive effects on an innovative commercial propeller-driven aircraft," AIAA Aviation 2019 Forum, 2019. doi: $10.2514 / 6.2019-2882$

[7] F. Nicolosi, A. De Marco, L. Attanasio, P. Della Vecchia, "Development of a Java-Based Framework for Aircraft Preliminary Design and Optimization," Journal of Aerospace Information System, Vol 13, pp. 234-242, 2016. doi: 10.2514/1.I010404

[8] V. Trifari, M. Ruocco, V. Cusati, F. Nicolosi, A. De Marco, "Java framework for parametric aircraft design-ground performance," Aircraft Engineering and Aerospace Technology (EMERALD); Volume 89, Issue 4, 2017. doi: 10.1108/AEAT-11-2016-0209

[9] F. Nicolosi, D. Ciliberti, P. Della Vecchia, S. Corcione, V. Cusati, “A comprehensive review of vertical tail design," Aircraft Engineering and Aerospace Technology, Vol. 89, Issue: 4, pp. 547-557, 2016. doi: 10.1108/AEAT-11-2016-0213

[10] D. Ciliberti, P. Della Vecchia, F. Nicolosi and A. De Marco, "Aircraft directional stability and vertical tail design: A review of semi-empirical methods,” Progress in Aerospace Sciences, Vol 95, pp. 140-172, 2017. doi: 10.1016/j.paerosci.2017.11.001

[11] F. Nicolosi, P. Della Vecchia, D. Ciliberti and V. Cusati, "Fuselage aerodynamics prediction methods," Aerospace Science and Technology, Vol 55, pp. 332-343, 2016. doi: 10.1016/j.ast.2016.06.012

[12] P. Della Vecchia, L. Stingo, F. Nicolosi, A. De Marco, E. Daniele, E. D'Amato, “Application of game theory and evolutionary algorithm to the regional turboprop aircraft wing optimization," Computational Methods in Applied Sciences, Vol 49, pp. 403-418, 2019. doi: $10.1007 / 978-3-319-89890-2 \_26$

[13] P. Della Vecchia, L. Stingo, S. Corcione, D. Ciliberti, F. Nicolosi, A. De Marco, "Game theory and evolutionary algorithms applied to MDO in the AGILE European project," 18th AIAA/ISSMO Multidisciplinary Analysis and Optimization Conference, 
2017.

doi: $10.2514 / 6.2017-4330$

[14] S. Corcione, V. Cusati, F. Nicolosi and D. Ciliberti, "Directional Stability Issues of a Three Lifting Surface Aircraft," Proceedings of the Italian Association of Aeronautics and Astronautics XXV International Congress, 2019.

[15] J.B. Barlow, W.H. Rae, A. Pope, Low-speed wind tunnel testing, 3rd ed., Wiley, New York, 1999.

[16] V. Cusati, F. Nicolosi, S. Corcione, D. Ciliberti and P. Della Vecchia, "Longitudinal stability issues including propulsive effects on an innovative commercial propeller-driven aircraft," AIAA Aviation 2019 Forum, 17-21 June 2019, Dallas (TX), 2019 .

doi: $10.2514 / 6.2019-2882$

[17] F. Diederich, "A plan-form parameter for correlating certain aerodynamic characteristics of swept wings," NACA TN2335, 1951.

[18] P. D. Chappell, R. W. Gilbey, et al. "Lift-curve slope and aerodynamic centre position of wings in inviscid subsonic flow," Item70011. Engineering Science Data Unit, 1970.

[19] J. Roskam, Airplane design part VI: preliminary calculation of aerodynamic, thrust and power characteristics, DAR Corporation, Lawrence (KS), 2000. ISBN: 1-884885-52-7.

[20] R.M. Bass, "Small scale wind tunnel testing of model propellers," Proceedings of 24 $4^{\text {th }}$ Aerospace Sciences Meeting (1986), https://doi.org/10.2514/6.1986-392.

[21] J.B. Brandt, M.S. Selig, "Propeller Performance Data at Low Reynolds Numbers," Proceedings of $49^{\text {th }}$ AIAA Aerospace. Sciences Meeting (2011), AIAA 2011-1255.

[22] R.W. Deters, G.K. Ananda, M.S. Selig, "Reynolds number effects on the performance of small-scale propellers," Proceedings of 32 ${ }^{\text {nd }}$ AIAA Applied Aerodynamics Conference, 2014. doi: $10.2514 / 6.2014-2151$

[23] D. Ciliberti, V. Cusati, P. Della Vecchia, S. Corcione, F. Nicolosi, "Powered wind tunnel tests setup of the IRON innovative turboprop aircraft," MATEC Web Conf. 304 02022, 2019. doi: 10.1051/matecconf/201930402022

[24] C.D. Perkins, R.E. Hage, Airplane Performance Stability and Control, Wiley, New York, 1949.

[25] P.C. Klein, "Parametric Modeling and Optimization of Advanced Propellers for Next-Generation Aircraft," M.Sc. Thesis TU Delft, 2017.

[26] H. Sobieczky, "Parametric Airfoil and Wings," Notes on Numerical Fluid Mechanics, pp. 71-88 (1998).

[27] Siemens STAR-CCM+ v2019.1 User Manual. 